\title{
Opportunities of the Digital Economy for Achieving Competitive Advantage of Firms
}

\author{
Elena Alexandrova \\ Department of World Economy and Management \\ Kuban State University \\ Krasnodar, Russia \\ E-mail: al-helen@mail.ru \\ Ksenia Shalenaya \\ Department of World Economy and Management \\ Kuban State University \\ Krasnodar, Russia \\ E-mail: ksunek_07@mail.ru
}

\author{
Marina Poddubnaya \\ Department of World Economy and Management \\ Kuban State University \\ Krasnodar, Russia \\ E-mail: 45f54@mail.ru \\ Sofia Savvidi \\ Department of World Economy and Management \\ Kuban State University \\ Krasnodar, Russia \\ E-mail: ssofiya@yandex.ru
}

\begin{abstract}
The present article studies the opportunities and constraints of the digital economy, that have a significant impact on how modern firms attain and sustain competitive advantage. Economic agents that manage to use digitalization of business to their best advantage get access to the most innovative methods of creating, delivering and obtaining product value. However, digital technologies also constitute threats to traditional competitive advantage, which greatly contributed to firms' successful performance in the market. The article discusses the tendencies of creating and developing competitive advantage, with the account taken of the turbulent business environment and the complexity of the digital environment where firms have to compete. The conclusion has been made on the need for a digital strategy to guide firms through opportunities and prospects of applying certain digital economy technologies. Another aspect of creating competitive advantage in the digital economy is related to developing cooperation within interorganizational networks. It is also essential to ensure coordinated actions on building long-term relationships with consumers, according to digital economy technologies being introduced, and creating competitive advantage.
\end{abstract}

Keywords - digital economy; competitive advantage; digital economy technologies; business processes

\section{INTRODUCTION}

Competitive potential of firms is based on their competitive advantage. The more competitive advantage an economic agent manages to attain, the more likely it is to increase its competitive ability. At the current stage of digital economy development there is no room for doubt over the importance and necessity of digital economy technologies, which cannot but encourage firms to approach their competitive advantage in a more responsible way.

The digital economy, provided by rapid advances in information and communication technology, including the
Internet, is shaping a new digital environment where all firms, from digital economy leaders to those wary of digital technologies, have to compete. In scientific literature, the changes in the business environment influenced by the digital economy are known as Industry 4.0 or the fourth industrial revolution, which is considered the symbiosis of the traditional material and the virtual world [1], [2].

According to one of the definitions, the digital economy is understood as "the economic activity that results from billions of everyday online connections among people, businesses, devices, data, and processes. The backbone of the digital economy is hyperconnectivity which means growing interconnectedness of people, organizations, and machines that results from the Internet, mobile technology and the internet of things (IoT)" [3].

Considering the role of the digital economy in successful business growth, it is essential not only to transform and optimize the internal processes of firms, but also to "understand the digital users" [4]. Meanwhile, "new technology and business strategies transform not only business processes, but also the way products and services are created and marketed, the structure and goals of the enterprise, the dynamics of competition, and all the rules for business success" [5]. It's important for firms to understand that digital economy technologies amount not merely to process automation, but primarily to new ways of doing business (e.g. improving customer service quality, operational optimization or developing new business models); only then the expectations of economic agents for investments in digital technologies will be met [6]. In order to unlock the potential of digital economy technologies, firms are required to develop their employees' management and technology skills. If economic agents do not accept new challenges, either deliberately or due to insufficient experience and skills, they lose their competitive advantage. 
solutions of the digital economy provide a range of opportunities for firms in developing their competitive advantage (together with profitability, revenue, and market value), ensuring their current and long-term competitive performance. Interpretation of the previous research on the topic makes it possible to identify some opportunities of the digital economy.

First, increased availability of digital technologies results in "positive network externalities that further accelerate the creation and availability of digital devices, networks, services, and contents" [11]. Moreover, expanding digital innovations reduce entry barriers for potential innovators, thereby making digital technologies more available for firms [12]. In other words, digital technologies development makes them more diverse and available for all firms, even for nondigital firms (digirati).

Second, digital technologies contribute to optimizing routine procedures and traditional activities inside firms: they allow reducing costs, increasing profitability of current assets, returns on new investments and business processes efficiency, and understanding customer needs better. The combination of low incremental costs and scalability of most information technologies allows the most successful firms to achieve results, which previously seemed impossible, in relatively short time. Therefore, digital firms (digirati) demonstrate better financial results, in comparison with the results of the firms, which are sceptical of digital technologies and use only e-mail, the Internet and some software (beginners) or intentionally disengage from digital technologies, even recognizing their effectiveness (conservatives) ("Fig. 1").

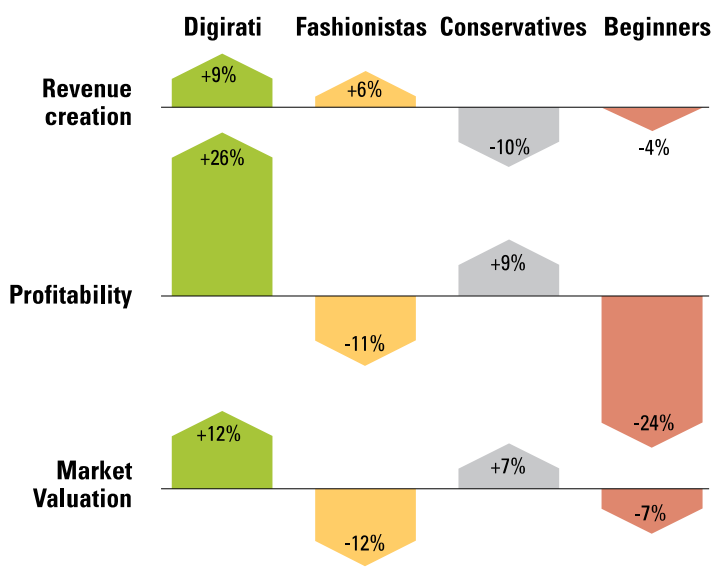

Fig. 1. Financial results of firms according to their receptiveness to digital technology.

a. Source: MIT's Centre for Digital Business and Capgemini report “The Digital Advantage: how digital leaders outperform their peers in every industry (http://ebooks.capgeminiconsulting.com/ the-digital-Advantage/index.html)".

Impressive achievements in information and communication technologies, such as digital convergence, Web 2.0, service-oriented architectures, cloud computing, communication networks, multiple data modelling, virtualization and simulation, distributed computing, Internet of things, blockchain, digital twins, augmented reality (AR), additive manufacturing, robots and cognitive technologies are reshaping the competitive landscape by bridging boundaries of time, distance, and function. These and other
Third, it is digitization "as the socio-technological process of applying digital technology across industries and contexts in ways that affect and shape their underlying infrastructures for the creation, storage, and distribution of content, applications, and services" [13]. For instance, ebooks are not just an advanced digital replacement for traditional books, but they also pose a serious challenge to the traditional business model of publishing houses that 
generation innovations. For example, social networks, mobile devices, analytics and embedded devices require a way of thinking and skills different from those demanded by previous transformation waves. Another possible constraint is that many firms, while recognizing the importance of digital technology, do not prioritize digital transformation of their business. They explain it with unawareness of where digital transformation will bring them.

So, the digital environment where modern firms have to compete is characterized as complex, turbulent, and fast moving. Under such conditions, creating competitive advantage is associated with a high level of uncertainty and risks for firms.

\section{DIRECTIONS FOR DEVELOPING COMPETITIVE ADVANTAGE IN THE DIGITAL ECONOMY}

provide ample opportunities for firms to create (develop) their competitive advantage, the constraints of digital transformation in firms' activities should also be taken into account.

To begin with, the sources of creating value and competitive advantage in the digital economy are established and based on unstable and constantly developing intangible assets, such as digital strategy and radical innovation, etc. [10]. Meanwhile, many firms find it quite difficult and often impossible (due to limited financial resources, lack of personnel, etc.) to monitor and maintain their intangible assets - the sources of competitive advantage in the digital economy. Therefore, it is advisable to use such dynamic competitive advantages of the digital economy to complement traditional factors of production, in case firms are aimed not only at surviving, but also at achieving high results in the digital economy. It is assumed that traditional factors of production are used effectively and the firm is able to create competitive advantage on their basis.

The next constraint is related to the fact that the introduction of digital technologies leads to intensified competition, thereby posing innovation-based threats to existing market leaders. For instance, in 1993-2013, in the US industries, which actively applied digital economy technologies, profit margins of leaders and laggards differed by 2-4 times. It illustrates that the principle of "the winner takes all" works in the most digitally developed sectors of the economy. Another remarkable example is Tinkoff Bank, having no bank offices, which in ten years became recognized as the largest independent bank of such a type in the world [8]. It is evident that each time the "winner" will be the firm that manages to create market value based on "new" innovations, thereby intensifying competition.

Despite the recognized need for digital transformation, most firms fail to achieve the anticipated outcomes and its visible benefits due to the lack of positive experience in managing transformation with digital technologies. So, possessing certain intangible assets and technologies of the digital economy does not guarantee success in attracting customers and expanding market shares. Using the existing assets of the digital economy effectively is much more important than possessing them. Moreover, even the firms whose leading positions have demonstrated their ability to apply digital technologies can face challenges from next-
Nevertheless, digital technologies do not just pose threats to traditional competitive advantage of firms (which provided firms' successful performance on the market for over a dozen years); they open up development opportunities based on the latest innovations. The analysis conducted by the Bain \& Company shows that over the past ten years, digital natives or post-millennials have generated $80 \%$ of the growth in market capitalization of the leading global firms [15].

It is considered that creating competitive advantage of firms in the digital economy requires accounting for the factors and specifics of the process in the digital environment.

Taking the opportunities of the digital economy for developing competitive advantage of firms presupposes several conditions and factors:

- resources necessary for discovering, understanding and creating new technologies. Not only do such resources refer to the firm's internal environment (e.g. financial opportunities), but they are also related to the external environment where it operates. It includes the availability of qualified and talented personnel in the country (the opportunities of human capital development), the level and quality of education and training, and production of scientific knowledge [16];

- the degree of technological development at the macro level, i.e. the general environment that allows developing digital technologies in a particular firm (industry). This includes favourable regulatory environment, the level of technological base development, investment opportunities;

- the level of the firms' commitment to digital transformation - its adaptability to digital economy technologies and flexibility in making decisions towards integrating digital technologies into business processes. Apparently, the discussed firm's commitment to digital transformation largely depends on the industry's and the country's commitment to digitalization. 
The understanding of how firms create and develop their competitive advantage in the digital economy is primarily based on key concepts of competitive advantage, with certain assumptions.

Thus, according to M. Porter's concept, strategic positioning of a firm in the selected industry clarifies the results of the firm towards the external environment [9]. The resource-based view highlights that firms can sustain competitive advantage by obtaining valuable, rare, imperfectly imitable and unique resources for a particular firm [17]. The presented approaches assume that the environment of the firm is relatively sustainable. However, the digital environment is described as complex, turbulent and fast changing. Value creation and competition are difficult to predict, which leads to a high degree of uncertainty. In this regard, some authors consider firm's interorganizational network as the primary source of sustained competitive advantage in the digital economy [12]. They mean dynamic and turbulent ecosystems, in which firms are embedded. Value is co-created with several other firms and strategy-making is based on shaping the environment. Thus, sustainable competitive advantage is created within interorganizational network. From a networkcentric perspective, firms' resources and capabilities extend beyond firm boundaries and are embedded in a set of relationships between firms.

In order to progress in the digital environment characterized by high uncertainty, a firm must clearly understand its current market position, including from the viewpoint of its capabilities in applying digital economy technologies. Analysing digital initiatives, the firm can identify strategic investment areas, as well as risks that need to be addressed on a first-priority basis. Firms not having a coordinated digital strategy frequently fail to achieve the expected competitive advantage. Furthermore, when identifying strategic activities in the digital environment, the firm should understand the main aspects of innovative development of the industry in which it operates.

The need to keep up-to-date with the latest technological trends and take every opportunity to make their business more efficient encourages firms to develop their competencies in digital economy technologies development and implementation. The choice of information technology is substantiated by financial opportunities of the firm itself and the expected effect of digitalization, as well as by product type and its acquisition. Thus, when optimizing costs and profit, the key point for a number of companies (e.g. for retail) is adapting the corresponding business model according to the desired level of consumer involvement, which requires selecting the most effective digital economy technology for each particular case. Products with high consumer involvement require positive, personalized experience, which implies using appropriate technology and top employees. For products with low consumer involvement, speed, efficiency and price are key factors, so automated sales channels will be the most preferable technology in this case.

\section{CONCLUSION}

Nowadays, the digital economy embraces almost every firm, regardless of how receptive to digital technology they are. The integration of digital economy technologies into business processes is affecting the dynamics of competition between firms. On the one hand, there are growing opportunities for creating competitive advantage, while on the other hand, this constitutes new challenges and threats to the development of existing firms and practical solutions to business problems. According to the research, the opportunities of the digital economy for companies in terms of developing competitive advantage include: availability of digital technologies; optimization of internal processes in companies; digitization; digital convergence. The problems that companies face in the digital economy has been identified in the study: the instability and high dynamism of competitive advantage provided by fast changing digital technologies; intensified competition; lack of management experience, lack of understanding of the high priority of digital transformation.

Impressive developments in digital technologies have resulted in the introduction of new features that have influenced the parameters of competitive advantage of firms. As modern firms develop their business models based on digital economy technologies, it is critical for them to have the appropriate opportunities to service new solutions. These opportunities require developing digital strategies, commitment to innovation and cooperation (building firm's interorganizational networks). It is also necessary to ensure coordinated actions on building long-term relationships with consumers, according to digital economy technologies being introduced, and creating competitive advantage. These requirements allow firms to develop competitive advantage, with the account taken of the uncertainty of the digital environment. Consequently, each firm has its own ideas on how to compete in the digital economy and individually identifies a set of its competitive advantages.

The conducted study does not intend to provide a comprehensive overview of all the opportunities and challenges of the influence the digital economy has on the development of competitive advantage of firms; however, consistent activity on monitoring and solving the existing prerequisites and constraints of business processes digitalization will significantly contribute to further advances in this direction.

\section{REFERENCES}

[1] P. Maresova, I. Soukal, L. Svobodova, M. Hedvicakova, E. Javanmardi, A. Selamat and O. Krejcar, "Consequences of industry 4.0 in business and economics". Economies 6(3), 46, 2018. http://dx.doi.org.aucklandlibraries.idm.oclc.org/10.3390/economies60 30046

[2] M. Melnik and T.Antipova, "Organizational Aspects of Digital Economics Management”. In: Antipova T. (eds) Integrated Science in Digital Age. ICIS 2019. Lecture Notes in Networks and Systems, vol 78. Springer, Cham, 2020. https://doi.org/10.1007/978-3-030-22493-6

[3] What is digital economy? Unicorns, transformation and the Internet of things. Deloitte. 
https://www2.deloitte.com/mt/en/pages/technology/articles/mt-whatis-digital-economy.html, last accessed 2019/10/07

[4] J. M. Leimeister, R. Winter, W. Brenner and J. Reinhard, "Research Program 'Digital Business \& Transformation IWI-HSG' (September 25, 2014)." University of St. Gallen's Institute of Information Management Working $\quad$ Paper 1. http://dx.doi.org/10.2139/ssrn.2501345

[5] D. Tapscott, The Digital Economy: Promise and Peril In The Age of Networked Intelligence: A Textbook, p. 368. McGraw-Hill, 1994.

[6] M. Fitzgerald, N. Kruschwitz, D. Bonnet and M. Welch, "Embracing In collaboration with Digital Technology. A New Strategic Imperative." MIT Center for Digital Business and Capgemini Consulting. $\quad$ https://www.capgemini.com/wpcontent/uploads/2017/07/embracing_digital_technology_a_new_strat egic_imperative.pdf

[7] International Data Corporation https://idcrussia.com/ru/research/published-reports

[8] Digital-Russia: New reality, july 2017. Digital McKinsey. https://www.mckinsey.com/ /media/mckinsey/locations/europe\%20a nd\%20middle\%20east/russia/our\%20insights/digital\%20russia/digital -russia-report.ashx

[9] M.E. Porter, Competitive Advantage. Creating and Sustaining Superior Performance. The Free Press, New York, 1998.

[10] B. Andersen and D. Wong, The New Normal Competitive advantage in the digital economy, October 2013. Big Innovation Centre (The Work Foundation and Lancaster University). http://www.biginnovationcentre.com/

[11] Y. Yoo, O. Henfridsson and K. Lyytinen, "The new organizing logic of digital innovation: An agenda for information systems research. Information systems research," 21(4):724-735, 2010.

[12] T. Koch and J. Windsperger, "Seeing through the network: Competitive advantage in the digital economy," Journal of Organization Design, 2017. Doi: 10.1186/s41469-017-0016-z.

[13] D. Tilson, K. Lyytinen and C. Sørenson, "Desperately seeking the infrastructure in IS research: Conceptualization of "digital convergence"," Proceedings of the 43rd Hawaii international conference on system sciences, Koloa, Kauai, HI, 2010.

[14] Y. Yoo, RJ. Jr. Boland, K. Lyytinen and A. Majchrzak, "Organizing for innovation in the digitized world," Organization science, 23(5):1398-1408, 2012.

[15] The Digital Enterprise Moving from experimentation to transformation. September 2018. World Economic Forum. www.weforum.org

[16] The IMD World Digital Competitiveness Ranking 2018 results. https://www.imd.org/wcc/world-competitiveness-centerrankings/world-digital-competitiveness-rankings-2018/

[17] J.B. Barney, "Firm resources and sustained competitive advantage," Journal of management, 17(1):99-120, 1991 